\title{
PROBLEMAS QUE PLANTEA LA DESCENTRALIZACIÓN PRODUCTIVA: LOS CONTRATOS PARA OBRA O SERVICIO ESPECÍFICO Y LA CAUSA OBJETIVA DE CONTRATACIÓN
}

\author{
Problems Raised by Productive Decentralization: \\ Contracts for a Specific Work or Service and The \\ Objective Cause of Contracting \\ Carlos Jiménez Silva \\ Universidad ESAN, Perú \\ https:/ / orcid.org/0000-0002-8338-8068
}

\section{Resumen}

Mediante el presente trabajo de investigación, se pretende demostrar que muchas veces se utiliza la institución de la descentralización productiva de la empresa como causa objetiva de la contratación por obra determinada o servicio específico, precarizando por este medio la relación laboral de los trabajadores. Por ello es necesaria una precisión normativa.

Palabras clave: descentralización productiva, descentralización del trabajo, contrato por obra o servicio específico, desnaturalización

\begin{abstract}
Through this research work, it is intended to show that the institution of productive decentralization of the company is often used as an objective cause of hiring for a specific work or specific service, thereby making the employment relationship of the workers precariously, for which a normative precision is necessary.
\end{abstract}

Keywords: Productive decentralization, decentralization of work, contract for specific work or service, denaturing 


\section{Introducción}

Es posible señalar que los sistemas productivos, entendidos como formas de prestación de un servicio en empresas de cualquier sector de la actividad económica, han estado relacionados principalmente con aspectos económicos; así, el debate se ha centrado en cómo generar empleo a partir de la inversión productiva y, sobre esta base, buscar justificaciones para que se flexibilice la legislación laboral —y en qué grado- con la finalidad de generar inversión productiva.

La teoría neoclásica señala que el desencuentro entre la oferta y la demanda en el mercado de trabajo es una de las formas en las que se genera el desempleo. Para evitarlo, se debe recurrir a mecanismos legales como la desregulación o flexibilidad de las normas, puesto que, a mayor regulación, se incrementa el desempleo. Una de las maneras en la que se produciría dicho desencuentro es cuando se establece la obligación del empleador de pagar a los trabajadores una remuneración mínima vital o de negociar colectivamente.

En sentido contrario, los institucionalistas señalan que se pueden hacer modificaciones normativas que faciliten el empleo, pero garantizando determinados derechos mínimos a través de normas de orden público de carácter irrenunciable. Dentro de estos mecanismos se encuentra la posibilidad de que las empresas adopten junto con sus trabajadores determinadas medidas que hagan posible sobrellevar una situación temporal de crisis como consecuencia de una menor demanda de bienes y servicios.

Estas medidas de carácter flexibilizador como instrumentos para la generación de empleo parten de corrientes de pensamiento vinculadas a los estados de desarrollo de los países en un determinado momento.

Simón Deakin señala que la primera corriente de pensamiento está asociada a la economía del desarrollo, de incremento de las leyes laborales protectoras del trabajador, generada por el crecimiento económico del mercado de mediados del siglo XX. La segunda visión, que ha sido la predominante desde la década del ochenta, es que las normas de protección de la legislación laboral son perjudiciales para el estado de desarrollo y deben reducirse para 
generar mercados más flexibles, a lo cual se añadiría que dicha situación se potencia en épocas de crisis como la que se vive actualmente ${ }^{1}$.

Estas medidas de flexibilidad se pueden plantear como solución en estados de emergencia originados por crisis sanitarias, económicas $u$ otras de similar magnitud, así como para enfrentar potenciales crisis futuras ${ }^{2}$.

De acuerdo con lo señalado, el panorama muestra un nuevo derecho del trabajo. Inicialmente, este tenía como centro la redistribución de poderes entre la parte fuerte de la relación laboral (la empleadora) y el trabajador, pues de esta forma se buscaba un equilibrio. Ahora, por el contrario, el escenario cambia y el centro del debate es cómo generar riqueza para mantener el empleo frente a una situación de crisis. A esto se suma el surgimiento de nuevas figuras que deben ser reguladas mediante la autonomía colectiva, como consecuencia de la externalización de las relaciones comerciales. Las políticas internas resultan ineficaces para controlar fenómenos económicos que trascienden sus fronteras.

Estos aspectos nos llevan a desarrollar la descentralización productiva como una nueva forma de desarrollo de gestión empresarial, mediante aquello que la doctrina ha denominado «tupamarización» del derecho del trabajo.

\section{La descentralización productiva y su diferencia con la descentralización del trabajo}

La producción mediante descentralización productiva está relacionada con la flexibilidad externa o numérica, y con la posibilidad de que el empleador pueda demandar la cantidad de empleo que necesita. Las razones pueden provenir del mercado de bienes y servicios. Por un lado, la demanda está sujeta a las oscilaciones del mercado; por otro, la oferta se presenta cuando existen razones de carácter tecnológico, tras haberse constatado en el país una aceleración de cambios tecnológicos, que justificarían la contratación de una empresa externa que se haga cargo de una parte del proceso productivo sin

1 Simón Deakin, , «Derecho laboral y desarrollo: nuevos conceptos y evidencias y su aplicación en América Latina», Sociedad Peruana de Derecho del Trabajo, en VII Congreso Nacional de Derecho del Trabajo y de la Seguridad Social (Lima: Sociedad Peruana de Derecho del Trabajo, 2016), 62-63.

2 Flexibilidad y Relaciones de Trabajo, http:/ / flexiseguridadrelacionesdetrabajo.blogspot.com 
tener que invertir en la adquisición de equipos. En el caso del Perú, no se tiene prevista la posibilidad de desvincular al trabajador bajo la forma de despido de carácter tecnológico, como consecuencia de cambios en el software o en los sistemas de producción ${ }^{3}$.

Esta descentralización empresarial supone que parte del proceso productivo, principal o complementario, sea ejecutado por un tercero, en forma colectiva o individual. Esto implica producir según la demanda de bienes y no mantener stock, por lo que la empresa contará con el personal mínimo para operar, lo estrictamente necesario.

En el sistema «toyotista» de relaciones productivas que surge en la década del setenta, se busca producir lo que es objeto de demanda, y se deja de lado el sistema de producción en masa y la mecanización del trabajo: el sistema «fordista» que se venía utilizando hasta entonces.

Esta descentralización, como un mecanismo de flexibilidad externa frente a la demanda de bienes o servicios, por el lado de la oferta, puede materializarse en el Perú de diversas formas individuales y colectivas.

Una de estas modalidades consiste en hacerlo a través de terceros, es decir, recurriendo a personas u empresas de tercerización o intermediación que de forma externa prestan determinados servicios a aquella organización que, debido a una mayor demanda $u$ oferta de los bienes o servicios que vende o produce, ha decidido descentralizar parte de su proceso productivo. En el caso de las personas naturales, de superarse la prueba de laboralidad, no existirá ningún tipo de vinculación laboral con la empresa contratante. En lo que respecta a las personas jurídicas, no se halla presente el elemento de prestación laboral, factor indispensable para que se establezca una relación de trabajo.

3 En España, el artículo 52.b) del Estatuto de los Trabajadores regula el despido por causas técnicas siempre y cuando se produzcan cambios en los medios e instrumentos de producción. El debate sobre cómo equilibrar tecnología y puestos de trabajo ya se está abordando en otros países. Moisés Barrio, letrado del Consejo de Estado y experto en derecho digital, relata cómo, según la cultura y posición de cada Estado ante la robotización, se están adoptando soluciones legales diversas ante este desafío. Así, en Corea del Sur o en los Emiratos Árabes Unidos la opinión predominante de los jueces es que debe fomentarse la automatización en el entorno laboral porque se entiende que ello multiplicará la productividad de la economía, y sus normativas avanzan en esta línea. En cambio, en Francia «entienden que la mejora de la competitividad sobre la base de la reducción de costes no puede configurarse como una causa justificadora del despido». Véase Irene Cortés, «Señoría, un robot me ha quitado el trabajo», El País, 7 agosto de 2020,https:/ / elpais.com/economia/2020-08-07/senoria-un-robot-me-haquitado-el-trabajo.html 
El mencionado test de laboralidad —en el caso de personas naturales-, parte de la premisa de que se realicen labores sin una subordinación jurídica, entendida como tal la facultad de mandar del empleador y la correlativa obligación de obedecer por parte del trabajador, teniendo en cuenta el principio de razonabilidad y las necesidades de la gestión del negocio.

En este aspecto, si bien es cierto que las libertades de empresa y de contratación - reconocidas en los artículos 2 (inciso 14) y 59 de la Constituciónpermiten al empresario celebrar contratos de locación de servicios para la prestación de servicios o contratos de carácter comercial, esto debe hacerse de buena fe y cuando no contravenga normas de orden público. Esto supone que un acuerdo no puede ir contra la presunción de laboralidad que supone la prestación de servicios en forma personal, remunerada y subordinada ${ }^{4}$.

En relación con el concepto de subordinación —entendido como la forma clásica de mandar y la correlativa obligación de obedecer dentro los límites de la razonabilidad-, en cuanto elemento diferenciador de otros tipos de contratos civiles y mercantiles y el campo de aplicación del derecho del trabajo, termina siendo cuestionable frente a las nuevas realidades. Este es el caso, por ejemplo, de los servicios efectuados sin una fiscalización inmediata y ajenos al giro del negocio, y en los que al trabajador no se le otorgan condiciones de trabajo. Por esta razón hace falta definir nuevos parámetros frente a esta nueva realidad, de modo que sea posible determinar si nos encontramos frente a una relación de trabajo.

En el caso peruano, a nivel jurisprudencial, tanto el Tribunal Constitucional como la Corte Suprema han señalado que existe una relación de trabajo cuando se hallan los siguientes elementos ${ }^{5}$ :

4 Artículo 4 del Decreto Supremo 003-97-TR, Ley de Productividad y Competitividad Laboral. El pleno jurisdiccional realizado en el año 2000, en la ciudad de Tarapoto, estableció que, si el juez constata la existencia de una relación laboral a pesar de la celebración de un contrato de locación de servicios o mercantil, debe preferir los principios de primacía de la realidad e irrenunciabilidad de derechos para determinar una relación laboral y el reconocimiento de derechos laborales. Al respecto, si bien estos plenos no tienen carácter vinculante, en tanto solo lo tienen los plenos casatorios, de acuerdo con el artículo 40 de la Ley Procesal del Trabajo - que a la fecha no hay-, sirven para concordar la jurisprudencia dispersa a nivel nacional, regional o distrital, de la especialidad a instancias de los órganos del Poder Judicial, conforme lo dispone el artículo 116 de la Ley Orgánica del Poder Judicial.

5 Sentencia del Tribunal Constitucional. El expediente 03015-2010-PA/TC y la Casación Laboral 0474-98-Lima del 5 de noviembre del 2001 señalan que dentro de una relación laboral no se pueden otorgar condiciones de trabajo, entendidas como las que facilitan la labor del trabajador. 


\begin{tabular}{|l|}
\hline Control de la prestación desarrollada o de la forma como se ejecuta. \\
\hline Integración del demandante en la estructura organizacional de la sociedad. \\
\hline Prestación ejecutada en un horario determinado. \\
\hline Prestación fue de cierta duración o continuidad. \\
\hline $\begin{array}{l}\text { Suministro de herramientas y materiales a la demandante para la prestación de servicios } \\
\text { (posición de la Corte Suprema en la casación 0474-98-LIMA del } 5 \text { de noviembre de 2001). }\end{array}$ \\
\hline Pago de remuneración al demandante. \\
\hline $\begin{array}{l}\text { Reconocimiento de derechos tales como las vacaciones anuales, las gratificaciones y los } \\
\text { descuentos para los sistemas de pensiones y salud. }\end{array}$ \\
\hline $\begin{array}{l}\text { Estos requisitos sirven para determinar si existió una relación de trabajo encubierta entre las } \\
\text { partes mediante un contrato civil. Se debe evaluar si en los hechos se presentaron, de forma } \\
\text { alternada y concurrente, alguno de los mencionados rasgos de laboralidad. }\end{array}$ \\
\hline
\end{tabular}

Dicho esto, se puede diferenciar la descentralización del trabajo de la productiva. La segunda puede ser de carácter individual o colectivo, y en este caso se realiza a través de empresas de tercerización de servicios, comerciales o entidades de intermediación laboral. Dado el carácter colectivo de la relación contractual en estas, se quiebra uno de los requisitos que deben existir de forma concurrente para que se presuma la existencia de un contrato de trabajo a plazo indeterminado, en tanto no hay prestación personal de servicios.

Asimismo, muchas veces se condiciona a las personas naturales para que, a cambio de su contratación, constituyan una persona jurídica, la cual termina siendo una fachada, en tanto existe una relación real entre la empresa contratante y el titular de la empresa contratada, al presentarse los elementos propios de una relación de trabajo. En tales casos se ha aplicado la figura de la despersonalización de la persona jurídica ${ }^{6}$.

6 El principio de despersonalización del empleador ha sido recogido en diversas sentencias, como la Casación 1696-2012-La Libertad, la Casación 2359-2012-Lima, Sentencia del Tribunal Constitucional 6322-2007-PA/TC, sentencia de la Cuarta Sala Laboral de la Corte Superior de Justicia de Lima, recaída en el expediente 24155-2013, sentencia de la Octava Sala Laboral de la Corte Superior de Justicia de Lima, recaída en el expediente 21730-2017, entre otras. No obstante que el artículo 51 de la Ley General de Sociedades señala que los accionistas no responden personalmente por las deudas sociales. A su vez, el artículo 78 del Código Civil señala que los miembros de las personas jurídicas son distintos de estas y no están obligados a satisfacer sus deudas. 
Se puede graficar la descentralización productiva mediante el presente esquema:

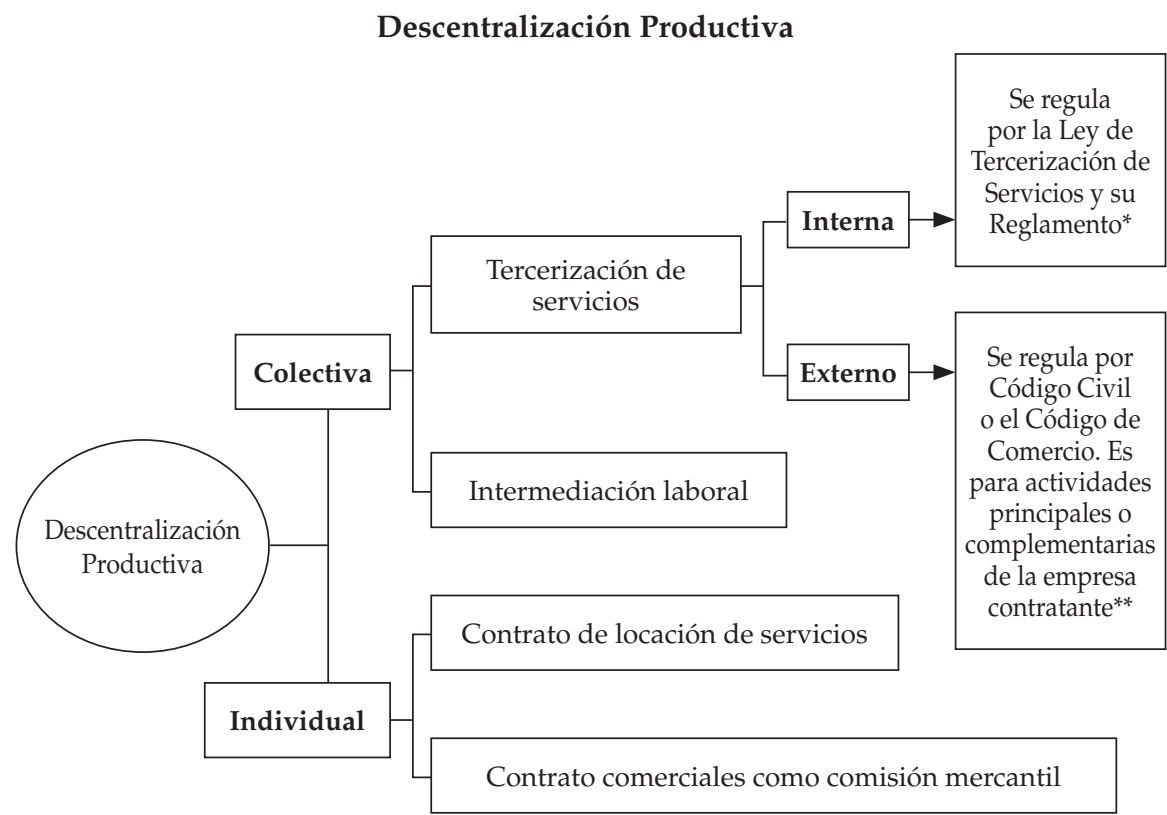

* Con desplazamiento contínuode personal a las instalaciones de la empresa contratante o de su centro de operaciones, cuandose trate de servicios propios de la empresa contratante los quese realizarán por la empresa contratista.

** No se aplica la Ley de Tercerización de Servicios ni su reglamento.

\section{El contrato por obra o servicio específico}

Teniendo en consideración la normativa peruana, este contrato supone el acuerdo de voluntades entre el empleador y el trabajador, que se materializa necesariamente por escrito, debiendo señalarse en forma expresa la causa objetiva de contratación; la duración será la que resulte necesaria para la realización de la obra o servicio contratado. Esto significa que no existe un plazo máximo de duración, por lo cual pueden hacerse las renovaciones que resulten necesarias hasta la conclusión o terminación de la obra o servicio objeto de contratación. 
Si el trabajador continúa prestando servicios luego de concluida la obra o servicio que es materia de contratación, se presume un contrato de trabajo a plazo indeterminado, salvo que exista una renovación del contrato sobre la base de la misma causa objetiva de contratación.

Con respecto a la renovación de los contratos sujetos a modalidad, se ha regulado en el Perú la obligación de renovarlos si la causa objetiva determinante de la contratación se mantiene. Para tal efecto se regulan los siguientes supuestos:

\begin{tabular}{|l|l|}
\hline Trabajadoras embarazadas. & Base legal: artículo 6 de la Ley 30709. \\
\hline Trabajadoras en periodo de lactancia. & Base legal: artículo 6 de la Ley 30709. \\
\hline $\begin{array}{l}\text { Trabajadora que presentó una queja de hos- } \\
\text { tigamiento sexual en el trabajo, presentación } \\
\text { de una demanda, denuncia o reclamación por } \\
\text { dicho motivo. }\end{array}$ & $\begin{array}{l}\text { Base legal: primera disposición complemen- } \\
\text { taria y modificatoria del Decreto Legislativo } \\
1410 .\end{array}$ \\
\hline $\begin{array}{l}\text { Participación como testigo en procedimien- } \\
\text { tos en favor de la víctima de acoso sexual. }\end{array}$ & $\begin{array}{l}\text { Base legal: primera disposición complemen- } \\
\text { taria y modificatoria del Decreto Legislativo } \\
1410 .\end{array}$ \\
\hline
\end{tabular}

Fuera de estos supuestos de excepción, no se establece obligación de renovar los contratos celebrados a plazo determinado. Tampoco es posible hacer interpretaciones extensivas ${ }^{7}$.

\section{Problemas que plantea el contrato por obra o servicio específico a partir de la descentralización productiva}

Los problemas se plantean a partir de determinar si es posible contratar a un trabajador por obra o servicio determinado para realizar labores propias del giro del negocio, en tanto se parte de la premisa de que se trata de un servicio

7 De acuerdo con lo establecido por el artículo 2 inciso 24 literal a) de la Constitución, nadie está obligado a hacer lo que la ley no manda ni impedido de hacer lo que la ley no prohíbe, siendo aplicable ello a las relaciones de carácter privado; de acuerdo con lo señalado por el Tribunal Constitucional en la sentencia 135-96/AP del 10 de junio de 1998, esta norma se aplica a las relaciones de carácter privado. 
de naturaleza permanente regulado como objeto social en los estatutos de la empresa. Si bien es cierto que ninguna norma especifica que esto constituya un fraude - y que, en consecuencia se desnaturaliza el contrato celebrado por obra o servicio determinado dando lugar, por consiguiente, a una relación de trabajo indeterminada-, existe una posición al respecto asumida por la Segunda Sala Transitoria de Derecho Constitucional y Social de la Corte Suprema de la República.

Dicho tribunal señaló que no se pueden celebrar contratos para realizar labores propias del giro del negocio de la empresa contratante, porque ello desnaturaliza el contrato por obra o servicio específico, considerándose este a plazo indeterminado ${ }^{8}$. Este pronunciamiento, sin embargo, no establece qué sucede cuando la causa objetiva que justifica la contratación de un trabajador por obra o servicio específico es un contrato comercial.

Al respecto, el Tribunal Constitucional, en este último supuesto, llega a la conclusión de que no se ha desnaturalizado el contrato por servicio específico $\mathrm{u}$ obra determinada, en tanto se puntualice que dicho contrato se ha celebrado sobre la base de una licitación ganada por Serpost, la cual es de carácter temporal y fue causa para que dicha empresa estatal — sujeta al régimen del Fonafe - requiera contratar bajo dicha modalidad contractual. Se entiende que si hay una causa objetiva para la contratación del trabajador —como lo es un contrato comercial con un tercero, incluso tratándose de labores propias del giro del negocio de la empresa contratante-, no se desnaturaliza este contrato, el cual se convierte en indeterminado'.

Asimismo, en el plano administrativo, el protocolo de fiscalización laboral de los contratos de trabajo sujetos a modalidad —documento normativo que establece reglas y criterios específicos para el adecuado ejercicio de la función inspectiva - señala de forma expresa que el inspector comisionado para determinar la validez de un contrato por obra o servicio específico puede solicitar el contrato civil que contenga la descripción de la ejecución de la obra

8 Casación Laboral 1529-2015-LIMA. Esta sentencia tienecarácter relativamentevinculante, desde el día siguiente de su publicación en el diario oficial El Peruano, pudiendo excepcionalmente los jueces apartarse de este criterio motivando adecuadamente su resolución, según el artículo 22 de la Ley Orgánica del Poder Judicial.

9 Sentencia del Tribunal Constitucional, recaída en el expediente 06553-2013-PA/TC del 21 marzo del 2015. 
o servicio que se va a contratar, entre otros documentos que acrediten su existencia, tales como el acuerdo de directorio, de gerencia, entre otros ${ }^{10}$.

De esta manera, el problema que se plantea a partir de estas interpretaciones es si resulta posible hacer una distinción a efectos de determinar la existencia de una desnaturalización de la forma de contratación, en función de que el trabajador haya sido contratado para una obra determinada o servicio específico que tenga como fin el desarrollo de un proyecto en particular o si puede ejecutar otros proyectos adicionales que eventualmente le pueda encargar la empresa que celebra el contrato comercial con su empleador.

\section{Supuesto de desnaturalización del contrato por obra o servicio a partir de la descentralización productiva}

De acuerdo con lo señalado en el punto anterior, se pueden establecer dos posiciones en cuanto a la desnaturalización o no del contrato por obra determinada o servicio específico.

La primera parte de la premisa de que no se desnaturaliza el contrato por obra determinada o servicio específico si la causa objetiva de la contratación depende de la ejecución de un proyecto determinado, desarrollado por el empleador del trabajador contratado bajo esta modalidad. El sustento sería el contrato civil o comercial que justifica esta forma de contratación.

La segunda posición que es posible adoptar parte de la premisa que se desnaturaliza esta forma de contratación por obra o servicio específico cuando la empresa que contrata al trabajador bajo esta modalidad de contrato de trabajo se dedica al desarrollo de proyectos o a la ejecución de obras contratadas por terceros. Este es el criterio reciente dado por la Cuarta Sala del Tribunal Supremo Español ${ }^{11}$.

Si se parte de esta segunda posición, la forma de contratación sería el incremento de actividades. En este caso específico se deberá acreditar, por ejemplo, el aumento de la facturación con el registro de ventas que demuestre que en el momento de la contratación del trabajador había un incremento de

10 Protocolo 003-2016-SUNAFIL/INNI, aprobado por Resolución de Superintendencia 071-2016-Sunafil, numeral 9.3.1.2 incisos a) y b).

11 Ver Wilfredo Sanguineti, «La subcontratación de actividades productivas y estabilidad en el empleo: el replanteamiento del modelo», Revista Trabajo y Derecho 75 (2021). 
los ingresos de la empresa contratante como consecuencia de la ejecución de obras o proyectos ${ }^{12}$. Esto será hasta un plazo máximo de tres años.

\section{Conclusiones}

1. Se puede utilizar la descentralización productiva como un mecanismo para mejorar la productividad de la empresa, pero también como una forma de justificar la precarización de los contratos de trabajo. Por esta razón deben establecerse herramientas para evitarlo en los casos de fraude contra la norma.

2. La contratación por una obra determinada o un servicio específico puede tener como causa objetiva la celebración de contratos civiles o comerciales con una tercera empresa, que es donde ejecutará sus labores el trabajador que prestará el servicio. Esto, de acuerdo con lo señalado por el Tribunal Constitucional en algunas sentencias y el protocolo de fiscalización de los contratos sujetos a modalidad.

3. Es importante establecer normativamente que, en los casos en que la empresa contratante del trabajador por obra determinada o servicio específico se dedique a realizar servicios específicos como contratista o empresa intermediaria, no puede celebrar este tipo de contratos, en tanto es parte de sus actividades habituales, propias del giro de su actividad.

4. En todo caso, se pueden establecer contratos a plazo fijo por incremento de actividades si se contrata al trabajador como producto del incremento de los servicios de la empresa contratante, lo que se acreditará con documentos, como el registro de ventas.

12 Dentro de los supuestos de contratación por inicio de actividades o incremento de estas, regulado por el artículo 57 del Decreto Supremo 003-97-TR, podemos encontrar en forma adicional a la actividad mencionada las siguientes: inicio de actividades productivas, lo que se puede acreditar con la constancia de inscripción de la constitución de la empresa o escritura, entre otros documentos; la instalación o apertura de nuevos establecimientos, lo que se puede acreditar por ejemplo con la autorización del nuevo inmueble para operar, y en caso de nuevas actividades, lo que se acredita con documentos, como licencia de funcionamiento municipal, registro de ventas y compras, entre otros. 


\section{Recomendaciones}

Se plantea modificar el artículo 77 del Decreto Supremo 003-97-TR, TUO del Decreto Legislativo 728, Ley de Productividad y Competitividad Laboral, estableciendo como causal de desnaturalización del contrato de trabajo por obra determinada o servicio específico la contratación del trabajador para realizar labores propias del giro del negocio de la empresa contratante del trabajador en forma directa o indirecta; en este último caso, a través de la celebración de contratos civiles o mercantiles con terceras empresas.

\section{Referencias}

Deakin, Simón. «Derecho laboral y desarrollo: nuevos conceptos y evidencias y su aplicación en América Latina». En VII Congreso Nacional de Derecho del Trabajo y de la Seguridad Social. Lima: Sociedad Peruana de Derecho del Trabajo, 2016.

Cortés, Irene. «Señoría, un robot me ha quitado el trabajo». El País, 7 de agosto de 2020. https:/ /elpais.com/economia/2020-08-07/senoria-un-robot-me-ha-quitado-eltrabajo.html

Flexibilidad y Relaciones de Trabajo. http:/ / flexiseguridadrelacionesdetrabajo.blogspot. com/

Sanguineti, Wilfredo. «La subcontratación de actividades productivas y estabilidad en el empleo: el replanteamiento del modelo». Revista Trabajo y Derecho 75 (2021).

\section{Sobre el autor}

Abogado. Magíster en Derecho del Trabajo y Seguridad Social por la Universidad Nacional Mayor de San Marcos. Curso de posgrado en Gestión de Talento Humano en la Universidad ESAN. Profesor en la Maestría de Derecho del Trabajo y Seguridad Social de la Universidad Nacional Mayor de San Marcos y de la Universidad de San Martín de Porres, profesor en la Universidad ESAN en la Facultad de Derecho Corporativo. Miembro de la Sociedad Peruana de Derecho del Trabajo y de la Seguridad Social. 